\title{
Crystallization and melting behavior of cocoa butter in lipid bodies of fresh cacao beans
}

Laura Bayés-García*a, Mercedes Aguilar-Jiménez, ${ }^{a}$,Teresa Calvet ${ }^{a}$, Tetsuo Koyano ${ }^{b}$, and Kiyotaka Sato ${ }^{c}$

aDepartament de Mineralogia, Petrologia i Geologia Aplicada, Facultat de Ciències de la Terra, Universitat de Barcelona, Martí i Franquès s/n, E-08028 Barcelona, Spain.

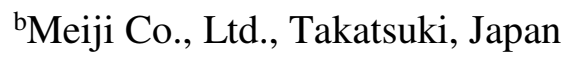

${ }^{\mathrm{c}}$ Faculty of Applied Biological Science, Hiroshima University, Higashi-Hiroshima, Japan.

KEYWORDS: Cocoa butter, crystallization, cacao beans, oil body, DSC, synchrotron radiation X-ray diffraction, germination

\section{ABSTRACT}

The present study aims at observing the crystallization and polymorphic behavior of cocoa butter (CB) in fresh cacao beans with DSC and X-ray diffraction techniques. Underlying idea of this study was to relate the necessary conditions of germination of cacao beans to the crystallization of $\mathrm{CB}$, which are present in oil-in-water emulsion droplets (lipid bodies) having 1 2 $\mu \mathrm{m}$ diameters. Different cooling and heating conditions, with rates of $15,2,0.5$ and $0.1{ }^{\circ} \mathrm{C} / \mathrm{min}$, were applied to 
fresh cacao beans and compared to bulk $\mathrm{CB}$. The results showed that the crystallization temperatures $\left(\mathrm{T}_{\mathrm{c}}\right)$ of $\mathrm{CB}$ in fresh cacao beans were lower than those of bulk $\mathrm{CB}$ at all the experimental conditions. In addition, polymorphic behavior of the occurrence of metastable and stable forms of CB was also different between the fresh cacao beans and the bulk state. The thermal behavior of fresh and dried cacao beans having different geographical origins was also analyzed. This study indicates that the germination conditions of cacao beans are extended to lowtemperature environmental areas by lowering $\mathrm{T}_{\mathrm{c}}$ of $\mathrm{CB}$ in fresh beans than of the bulk oil. The results were consistent with the germination experiments of fresh cacao beans at different temperatures.

\section{INTRODUCTION}

Chocolate is a solid system formed by a cocoa butter (CB)-continuous matrix containing dispersed particles of cacao mass, sugar and other ingredients. Within this complex microstructure, $\mathrm{CB}$ crystals are determinant for the unique sensory characteristics of flavor release, mouthfeel and melting properties of chocolate, which is manufactured from the beans of Theobroma cacao. When cacao pods ripen, they are harvested by cutting them directly from the trunk of the tree and, when opened, several cacao beans, which are covered by a white mucilaginous pulp, are extracted. Immediately following harvesting, cacao beans are subjected to fermentation and drying processes, during which flavor precursors are developed.

Cacao beans are dicotyledonous seeds, as they consist of two cotyledons and a small embryo, which are protected by a shell called testa (see schematic illustration in Figure 1). 


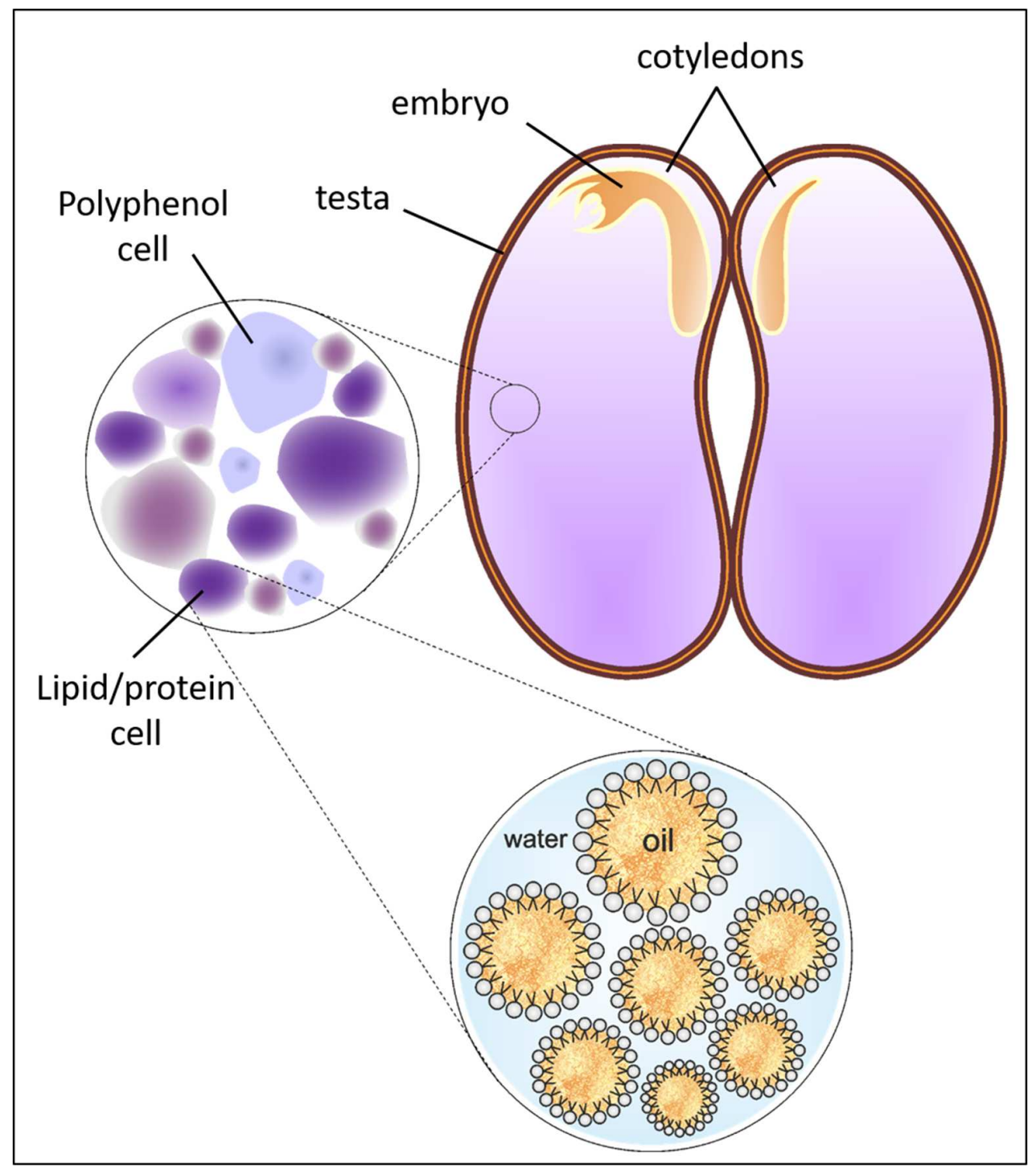

Figure 1. Schematic representation of fresh cacao bean containing lipid/protein cells with oil-inwater native emulsion or lipid bodies.

Cotyledons may become the embryonic primary leafs when the seed germinates, but they also contain storage cells for the development of the seedling. The most abundant cell types are tiny lipid/protein storage cells, which contain a large number of lipid vacuoles embedded in 
cytoplasm. Thus, most of the energy is stored in the form of native oil-in-water emulsion, that is to say, in lipid droplets or lipid bodies mainly constituted by $\mathrm{CB}$, which represent almost the $50 \%(\mathrm{w} / \mathrm{w})$ in fresh cacao beans, as shown in Table $1 .^{1,2}$ Lipid bodies are, therefore, dynamic cellular organelles that serve as important reservoirs of lipids, but also as substrates for multiple cellular processes. The lipids contained are surrounded by a phospholipid monolayer and associated proteins, and this surface composition becomes determinant for regulating lipid bodies size and their ability to interact with other lipid bodies or organelles. ${ }^{3,4}$

Table 1. Approximate composition of fresh cacao beans. ${ }^{2}$

\begin{tabular}{|l|l|}
\hline Component & Average concentration (\% w/w) \\
\hline Water & $35-45$ \\
\hline Lipids & $45-55$ \\
\hline Polysaccharides & $14-20$ \\
\hline Sugars (sucrose, glucose, fructose) & $0.5-2.0$ \\
\hline Pectin & 2.0 \\
\hline Proteins & 1.5 \\
\hline Polyphenols & $7.0-10.0$ \\
\hline Alkaloids (theobromine, caffeine) & 3.5 \\
\hline Others & $0.8-1.9$ \\
\hline
\end{tabular}

Cocoa butter can crystallize in six different polymorphic forms (form I to VI) and, among them, form $\mathrm{V}$ is industrially promoted due to its unique texture, snap, gloss, melting, and mouthfeel characteristics. ${ }^{5}$ Much research has been carried out on the crystallization and polymorphic 
behavior of $\mathrm{CB}$ and its three main component triacylglycerols (TAGs), which are 1,3dipalmitoyl-2-oleoyl-glycerol (POP), 1,3-distearoyl-2-oleoyl-glycerol (SOS), and rac-palmitoylstearoyl-2-oleoyl-glycerol (POS). ${ }^{6-12}$ However, to the best of our knowledge, most work related to the crystallization behavior of $\mathrm{CB}$ was carried out by using $\mathrm{CB}$ in bulk state.

In the present work, we studied the crystallization and polymorphic behavior of the $\mathrm{CB}$ in fresh cacao beans, aiming at relating them to germination behavior of cacao bean. $\mathrm{CB}$ are present in lipid bodies in fresh cacao beans and it comprises more than $50 \%$ among three nutrients together with proteins and carbohydrates in dried matters of cacao nibs. It is hypothesized that the crystallization of CB in the lipid bodies at chilled temperatures may negatively affect the germination behavior of cacao beans, and this is one of the reasons why cacao tress can survive solely at tropical areas.

The results thus obtained were compared with $\mathrm{CB}$ in bulk state at the same experimental conditions, as crystallization behavior in emulsion droplet is different from bulk crystallization. ${ }^{13}$ In order to monitor the occurrence of different polymorphic forms, we selected varied thermal treatments based on different cooling and heating rates. The influence of dynamic temperature variations on the polymorphic behavior of main TAGs of edible fats and oils was already analyzed by our group, ${ }^{10,14-16}$ and the results demonstrated that desired polymorphic forms with specific physicochemical properties may be obtained by tailoring appropriate dynamic thermal treatments.

We also compared crystallization temperatures of $\mathrm{CB}$ in fresh beans and bulk state. The observation of the crystallization behavior of $\mathrm{CB}$ in fresh cacao beans with differential scanning calorimetry (DSC) and synchrotron radiation X-ray diffraction (SR-XRD) may permit to relate 
the necessary conditions of germination of cacao beans, which are strongly determined by its presence in oil-in-water emulsion droplets.

Fresh cacao beans were selected prior to fermentation, as enzymatic changes during fermentation involve obvious structural modifications, such as the re-deposition of lipids within cells, which may modify the crystallization behavior of CB. ${ }^{1}$ Thermal behavior of fresh and dried cacao beans having different geographical origins was also examined.

Finally, the crystallization behavior of $\mathrm{CB}$ in fresh cacao beans was corroborated with rhizogenesis experiments of Theobroma cacao at different temperatures. It has been known that the temperatures of cacao-growing conditions affect fatty acid compositions and growth rate of cacao cell suspension cultures. ${ }^{17,18}$ To our best knowledge, this study is the first to relate the crystallization behavior of $\mathrm{CB}$ in fresh cacao beans to the germination of cacao beans.

\section{EXPERIMENTAL SECTION}

\section{Materials}

Dominican Republic (Cibao region) ripe fruits of Theobroma cacao of the Trinitario variety were obtained from the Comisión Nacional del Cacao (Santo Domingo, Dominican Republic) through Chocolates Comes S.L. (Sueca, Spain). India and Colombia ripe cacao fruits were obtained through IBK Tropic S. A. (Barcelona, Spain). India fruits were grown in Idukki, which is located in the south area, whereas Colombia fruits were obtained from the northern town San Vicente de Chucuri. Philippines cacao fruits of the Trinitario variety were grown in Mindanao Island, located in the south area of Philippines. Vietnam ripe fruits were obtained from Ben Tre 
province, located in the south west of Ho Chi Minh City. Immediately after removal from the pods, white mucilage covering the beans was removed, and cacao beans samples were kept in the freezer.

The cocoa butter used was donated by Simon Coll Xocolaters S.A. (Sant Sadurní d'Anoia, Spain).

\section{Differential scanning calorimetry}

Differential scanning calorimetry (DSC) experiments were conducted at atmospheric pressure using a PerkinElmer Diamond instrument. Samples were weighed into $50 \mu \mathrm{L}$ aluminum pans, and covers were sealed into place. The instrument was calibrated with reference to the enthalpy and the melting points of indium $\left(\mathrm{T}_{\mathrm{m}}=156.6{ }^{\circ} \mathrm{C} ; \Delta \mathrm{H}=28.45 \mathrm{~J} / \mathrm{g}\right)$ and decane $\left(\mathrm{T}_{\mathrm{m}}=-29.7{ }^{\circ} \mathrm{C}\right.$; $\Delta \mathrm{H}=202.1 \mathrm{~J} / \mathrm{g}$ ) standards. An empty pan was used for reference. Dry nitrogen was used as purge gas in the DSC cell at $20 \mathrm{~cm}^{3} / \mathrm{min}$. Thermograms were analyzed using Pyris Software to obtain the enthalpy (J/g, integration of the DSC signals) and peak top $\mathrm{T}, \mathrm{T}_{\mathrm{onset}}$, and $\mathrm{T}_{\text {end }}$ of the transitions $\left({ }^{\circ} \mathrm{C}\right.$, intersections of the baseline and the initial and final tangents at the transition). Three independent measurements were made for each experiment $(n=3)$. Random uncertainty was estimated with a 95\% threshold of reliability using the Student's method.

Samples of Dominican Republic fresh cacao beans and CB were subjected to varied dynamic thermal treatments based on the application of different cooling and heating rates. Thus, samples were cooled from $55{ }^{\circ} \mathrm{C}$ to $-80{ }^{\circ} \mathrm{C}$ and reheated to $55^{\circ} \mathrm{C}$ at the rates of $15,2,0.5$ and $0.1{ }^{\circ} \mathrm{C} / \mathrm{min}$. DSC results were complemented and interpreted with X-ray diffraction experiments, using laboratory-scale or synchrotron radiation source, at the same experimental conditions. A 
correction (described elsewhere ${ }^{19}$ ) was applied for analyses with cooling or heating rates other than $2^{\circ} \mathrm{C} / \mathrm{min}$, since the calorimeter was calibrated at this rate.

DSC experiments based on cooling and heating of $2{ }^{\circ} \mathrm{C} / \mathrm{min}$ were also conducted in fresh and dried cacao beans with other geographical origins (India, Colombia and Philippines).

\section{Laboratory-Scale X-ray Diffraction}

Laboratory-scale powder XRD experiments were performed by using a PANalytical X'Pert Pro MPD powder diffractometer of $240 \mathrm{~mm}$ of radius, in a configuration of convergent beam with a focalizing mirror and a transmission geometry with a spinner glass capillary sample holder, and equipped with a PIXcel detector. The equipment also included an Oxford Cryosystems 700 series Cryostream liquid nitrogen cryostat, enabling temperature control of the analyzed capillary sample from 90 to $500 \mathrm{~K}$. Monochromatic $\mathrm{Cu} \mathrm{K} \alpha 1(\lambda=0.154059 \mathrm{~nm})$ radiation was selected by means of a Hybrid Monochromator. The sample was introduced in a $1.5 \mathrm{~mm}$-diameter Lindemann glass capillary, which was rotated about its axis during the experiment to minimize preferential orientations of the crystallites. The step size was $0.026^{\circ}$ from $1^{\circ}$ to $28^{\circ} 2 \theta$ and the measuring time of $75 \mathrm{~s}$ per step. X'Pert HighScore software was used to process XRD data.

\section{Synchrotron Radiation X-ray Diffraction}

Synchrotron radiation X-ray diffraction (SR-XRD) experiments were conducted on beamline BL11-NCD-SWEET at the synchrotron ALBA (Cerdanyola del Vallès, Barcelona, Spain) at 12.4 
$\mathrm{keV}$. The sample-detector distance was $2.2 \mathrm{~m}$. X-ray scattering data were collected on a Pilatus $1 \mathrm{M}$ detector with a pixel size of $172 \times 172 \mu \mathrm{m}^{2}$ for the small-angle X-ray diffraction (SAXD) data and on a LX255-HS Rayonix detector with a pixel size of $44 \times 44 \mathrm{~mm}^{2}$ for the wide-angle X-ray diffraction (WAXD) data. The temperature of the sample was controlled by a Linkam stage. SR-XRD experiments were particularly required for thermal treatments based on high cooling and heating rates of $15{ }^{\circ} \mathrm{C} / \mathrm{min}$. However, SR-XRD patterns were also acquired for cooling-heating processes carried out at 2 and $0.5^{\circ} \mathrm{C} / \mathrm{min}$. The sample was placed in an aluminum sample cell with a Kapton film window. The q-axis calibration was obtained by measuring silver behenate for SAXD and $\mathrm{Cr}_{2} \mathrm{O}_{3}$ for WAXD. The program pyFAI was used to integrate the 2D WAXD into the 1D data; the SAXD data were processed with in-house software.

\title{
Rhizogenesis experiments
}

Vietnam cacao beans were subjected to rhizogenesis experiments, which consisted of determining stem and root shooting when fresh beans remained several days at fixed temperatures. Then, fresh beans were washed to remove gel-like white pulp and set, under wet conditions, at fixed temperatures of 17,20 and $32{ }^{\circ} \mathrm{C}$ for 15 days.

\author{
RESULTS AND DISCUSSION
}

Polymorphic crystallization and transformation behavior 
Figure 2 shows the polymorphic behavior of cocoa butter in bulk (left side in Figure 2) and fresh cacao beans (right side) determined when samples were cooled from $55^{\circ} \mathrm{C}$ to $-80{ }^{\circ} \mathrm{C}$ at a rate of $15{ }^{\circ} \mathrm{C} / \mathrm{min}$ and reheated to $55^{\circ} \mathrm{C}$ at the same rate.

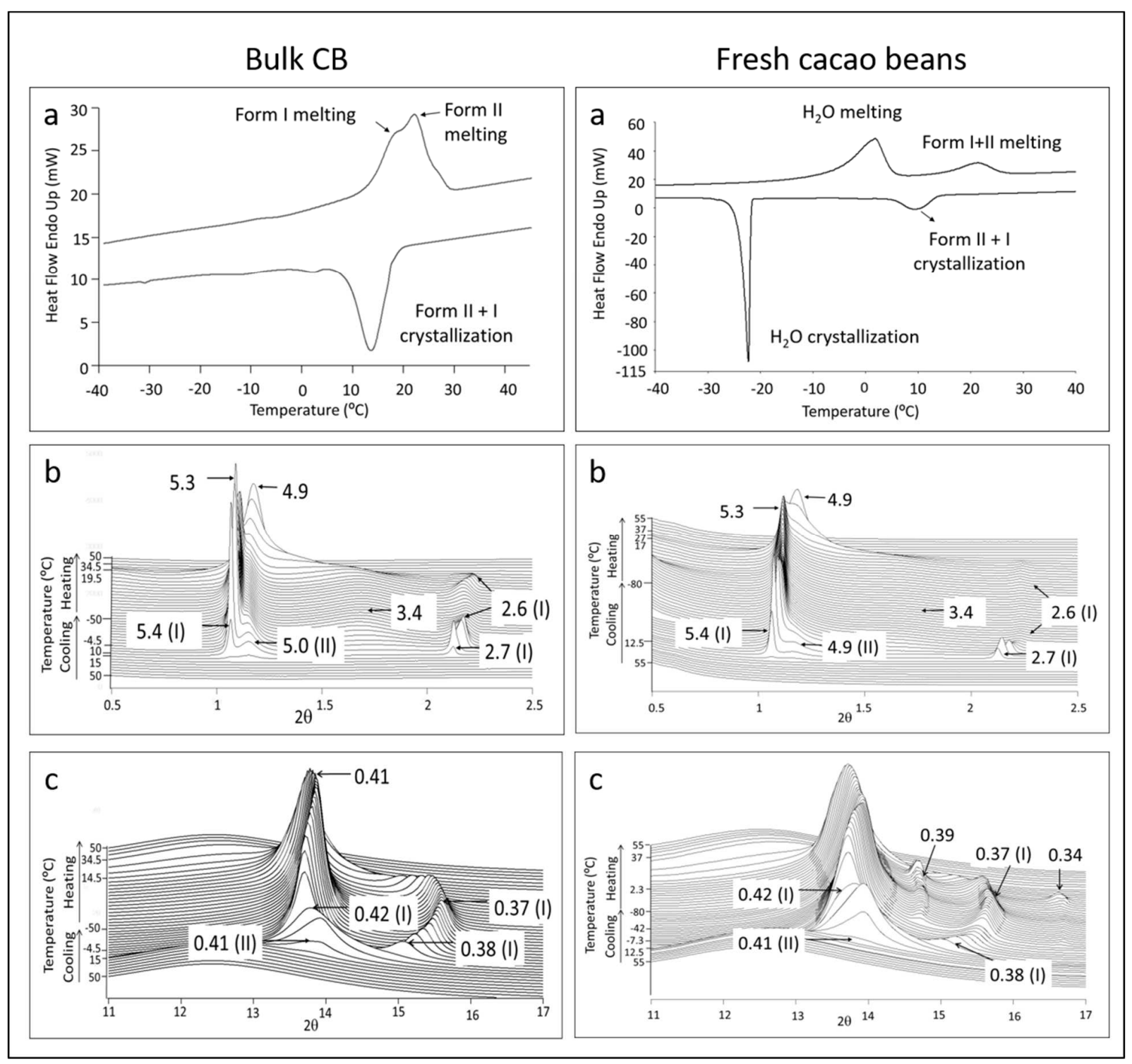

Figure 2. Polymorphic behavior of $\mathrm{CB}$ when cooled and heated at $15^{\circ} \mathrm{C} / \mathrm{min}$. Bulk $\mathrm{CB}$ (left side);

a) DSC thermogram; b) SR-SAXD pattern; c) SR-WAXD pattern. Fresh cacao beans (right side);

a) DSC thermogram; b) SR-SAXD pattern; c) SR-WAXD pattern. 
By cooling bulk CB at such a high rate, the DSC thermogram (Figure 2a, Bulk CB) exhibited a pronounced exothermic peak with $\mathrm{T}_{\text {onset }}$ of $16.6^{\circ} \mathrm{C}( \pm 0.5)$ (see Table 2), which, according to the SR-XRD data, corresponded to a concurrent crystallization of metastable forms I and II. 
Table 2. DSC data of crystallization and transformation of CB polymorphs in bulk State and fresh cacao beans obtained by cooling and heating rates of $15,2,0.5$ and $0.1{ }^{\circ} \mathrm{C} / \mathrm{min}$. The letters, $c$ and $m$, in parentheses mean crystallization and melting. 


\begin{tabular}{|c|c|c|c|c|c|c|c|c|}
\hline & \multicolumn{2}{|c|}{ Cooling at $15^{\circ} \mathrm{C} / \mathrm{min}$} & \multicolumn{2}{|c|}{ Heating at $15^{\circ} \mathrm{C} / \mathrm{min}$} & & & & \\
\hline \multirow[t]{3}{*}{ CB Bulk } & \multicolumn{2}{|l|}{$\mathrm{I}+\mathrm{II}(\mathrm{c})$} & \multicolumn{2}{|l|}{$\mathrm{I}+\mathrm{II}(\mathrm{m})$} & & & & \\
\hline & $\mathrm{T}_{\text {onset }}$ & $\mathrm{T}_{\mathrm{end}}$ & $\mathrm{T}_{\text {onset }}$ & $\mathrm{T}_{\text {end }}$ & & & & \\
\hline & $16.6 \pm 0.5$ & $5.0 \pm 1.3$ & $11.2 \pm 0.4$ & $27.7 \pm 1.1$ & & & & \\
\hline \multirow[t]{4}{*}{ CB Fresh Bean } & \multicolumn{2}{|l|}{$\mathrm{I}+\mathrm{II}(\mathrm{c})$} & \multicolumn{2}{|l|}{$\mathrm{I}+\mathrm{II}(\mathrm{m})$} & & & & \\
\hline & $\mathrm{T}_{\text {onset }}$ & $T_{\text {end }}$ & $\mathrm{T}_{\text {onset }}$ & $\mathrm{T}_{\text {end }}$ & & & & \\
\hline & $12.9 \pm 0.7$ & $5.9 \pm 1.3$ & $12.5 \pm 1.8$ & $25.9 \pm 1.8$ & & & & \\
\hline & \multicolumn{4}{|c|}{ Cooling at $2^{\circ} \mathrm{C} / \mathrm{min}$} & \multicolumn{3}{|c|}{ Heating at $2^{\circ} \mathrm{C} / \mathrm{min}$} & \\
\hline \multirow[t]{3}{*}{ CB Bulk } & \multicolumn{2}{|l|}{ II (c) } & \multicolumn{2}{|l|}{$\mathrm{I}(\mathrm{c})$} & $\mathrm{I} \rightarrow \mathrm{III}$ & \multicolumn{2}{|l|}{$\mathrm{II}+\mathrm{III}(\mathrm{m})$} & \\
\hline & $\mathrm{T}_{\text {onset }}$ & $\mathrm{T}_{\mathrm{end}}$ & $T_{\text {onset }}$ & $\mathrm{T}_{\text {end }}$ & $\mathrm{T}_{\text {onset }}$ & $\mathrm{T}_{\text {onset }}$ & $\mathrm{T}_{\text {end }}$ & \\
\hline & $21.1 \pm 1.8$ & $17.4 \pm 0.4$ & $16.5 \pm 0.6$ & $9.8 \pm 1.5$ & $13.3 \pm 0.8$ & $17.5 \pm 0.3$ & $28.6 \pm 0.9$ & \\
\hline \multirow[t]{4}{*}{ CB Fresh Bean } & \multicolumn{2}{|l|}{ II (c) } & & & \multicolumn{2}{|c|}{$\mathrm{II} \rightarrow \mathrm{IV} / \mathrm{IV}(\mathrm{m})$} & & \\
\hline & $\mathrm{T}_{\text {onset }}$ & $T_{\text {end }}$ & & & $\mathrm{T}_{\text {onset }}$ & $T_{\text {end }}$ & & \\
\hline & $16.4 \pm 1.6$ & $11.1 \pm 1.8$ & & & $15.9 \pm 1.9$ & $27.7 \pm 1.8$ & & \\
\hline & \multicolumn{3}{|c|}{ Cooling at $0.5^{\circ} \mathrm{C} / \mathrm{min}$} & \multicolumn{4}{|c|}{ Heating at $0.5^{\circ} \mathrm{C} / \mathrm{min}$} & \\
\hline \multirow[t]{2}{*}{ CB Bulk } & II (c) & \multicolumn{2}{|l|}{$\mathrm{I}(\mathrm{c})$} & \multicolumn{2}{|c|}{$\mathrm{IV}(\mathrm{c}) / \mathrm{II}(\mathrm{m})$} & \multicolumn{2}{|l|}{ IV (m) } & \\
\hline & $\mathrm{T}_{\text {onset }}$ & $\mathrm{T}_{\text {onset }}$ & $\mathrm{T}_{\mathrm{end}}$ & $\mathrm{T}_{\text {onset }}$ & $\mathrm{T}_{\mathrm{end}}$ & $\mathrm{T}_{\text {onset }}$ & $\mathrm{T}_{\mathrm{end}}$ & \\
\hline
\end{tabular}




\begin{tabular}{|c|c|c|c|c|c|c|c|c|}
\hline & $22.9 \pm 0.4$ & $16.4 \pm 0.3$ & $7.5 \pm 1.0$ & $19.6 \pm 0.6$ & $29.8 \pm 0.8$ & $30.7 \pm 0.5$ & $34.4 \pm 0.8$ & \\
\hline \multirow[t]{4}{*}{ CB Fresh Bean } & \multicolumn{2}{|l|}{ II (c) } & & \multicolumn{2}{|c|}{$\mathrm{II} \rightarrow \mathrm{IV} / \mathrm{IV}(\mathrm{m})$} & & & \\
\hline & $T_{\text {onset }}$ & $T_{\mathrm{end}}$ & & $\mathrm{T}_{\text {onset }}$ & $\mathrm{T}_{\mathrm{end}}$ & & & \\
\hline & $16.6 \pm 1.1$ & $12.0 \pm 1.0$ & & $17.3 \pm 0.7$ & $30.0 \pm 0.5$ & & & \\
\hline & \multicolumn{4}{|c|}{ Cooling at $0.1^{\circ} \mathrm{C} / \mathrm{min}$} & \multicolumn{4}{|c|}{ Heating at $0.1^{\circ} \mathrm{C} / \mathrm{min}$} \\
\hline \multirow[t]{3}{*}{ CB Bulk } & \multicolumn{2}{|l|}{ II (c) } & \multicolumn{2}{|l|}{$\mathrm{III}+\mathrm{IV}(\mathrm{c})$} & \multicolumn{2}{|l|}{$\mathrm{II}+\mathrm{III}(\mathrm{m})$} & \multicolumn{2}{|c|}{$\mathrm{IV} \rightarrow \mathrm{V} / \mathrm{V}(\mathrm{m})$} \\
\hline & $\mathrm{T}_{\text {onset }}$ & $\mathrm{T}_{\text {end }}$ & $\mathrm{T}_{\text {onset }}$ & $\mathrm{T}_{\mathrm{end}}$ & $\mathrm{T}_{\text {onset }}$ & $\mathrm{T}_{\mathrm{end}}$ & $\mathrm{T}_{\text {onset }}$ & $\mathrm{T}_{\text {end }}$ \\
\hline & $24.6 \pm 1.6$ & $20.8 \pm 0.8$ & $18.6 \pm 1.6$ & $15.6 \pm 1.2$ & $18.3 \pm 0.8$ & $24.8 \pm 0.5$ & $28.0 \pm 1.1$ & $34.6 \pm 0.7$ \\
\hline \multirow[t]{3}{*}{ CB Fresh Bean } & \multicolumn{2}{|l|}{$\mathrm{III}+\mathrm{IV}(\mathrm{c})$} & & & & & & \\
\hline & $\mathrm{T}_{\text {onset }}$ & $\mathrm{T}_{\mathrm{end}}$ & & & & & & \\
\hline & $18.8 \pm 1.8$ & $12.3 \pm 0.4$ & & & & & & \\
\hline
\end{tabular}


In more detail, initial form II was firstly detected with the occurrence of SR-SAXD peak at 5.0 $\mathrm{nm}$ (Figure 2b, Bulk CB) and SR-WAXD peaks at $0.41 \mathrm{~nm}$ (Figure 2c, Bulk CB) and, soon after when cooling, form I occurred with typical SR-SAXD peaks at 5.4 and $2.7 \mathrm{~nm}$, and SR-WAXD peaks at 0.42 and $0.38 \mathrm{~nm}$. Although very broad and flat exothermic phenomenon, with peak top temperature at around $-10{ }^{\circ} \mathrm{C}$, was observed on further cooling, no changes were revealed in the SR-XRD patterns. Regarding the subsequent heating process, a main endotherminc peak with $\mathrm{T}_{\text {onset }}$ of $11.2^{\circ} \mathrm{C}( \pm 0.4)$ appeared in the corresponding heating thermogram, which was due to the melting of the previously crystallized forms I and II, as the SR-XRD data demonstrated with the vanishing of the corresponding peaks.

The same dynamic thermal treatment was applied to fresh cacao beans and significant differences were detected compared to the bulk CB case. Most important variations were related to the initial crystallization temperatures, as shown in Table 2 . Thus, at approximately $12.9{ }^{\circ} \mathrm{C}$, that is at a temperature almost $4{ }^{\circ} \mathrm{C}$ lower than that of bulk $\mathrm{CB}$, an exothermic signal was observed on the DSC cooling curve (Figure 2a, Fresh cacao beans). This was assigned to form II and I crystallization, as the SR-SAXD pattern exhibited the occurrence of small-angle diffraction peaks at $4.9 \mathrm{~nm}$ (Form II) and at 5.4 and $2.7 \mathrm{~nm}$ (Form I), and wide-angle diffraction peaks at $0.41 \mathrm{~nm}$ (Form II), and 0.42 and $0.38 \mathrm{~nm}$ (Form I) (see Figure 2b and 2c, Fresh cacao beans, respectively). On further cooling, the DSC thermogram showed the presence of a sharp exothermic phenomenon with peak top temperature at around $22{ }^{\circ} \mathrm{C}$, which was due to the crystallization of the water contained in fresh cacao beans. Ice crystals melted at approximately $0{ }^{\circ} \mathrm{C}$ (peak top temperature), as shown in the corresponding DSC heating thermogram and, afterwards and similarly to bulk CB, Form II and I melted (onset temperature of $12.5 \pm 1.8{ }^{\circ} \mathrm{C}$ ), which was confirmed by the disappearance of SR-XRD peaks. By comparing the SR-XRD patterns of the two samples, one 
may note significant differences in the relative intensity of the peaks. In more detail, form I peaks became more intense than those of form II in bulk $\mathrm{CB}$, whereas the peaks intensity of the two forms became comparable in fresh cacao beans. This means that higher amount of metastable form I was obtained in bulk, and higher amount of more stable form II could be obtained in fresh beans at the same experimental conditions.

More complex polymorphic behavior was observed when the two samples were subjected to intermediate cooling/heating conditions of $2{ }^{\circ} \mathrm{C} / \mathrm{min}$. Figure 3 depicts the polymorphic behavior of bulk CB (left side) and fresh cacao beans (right side) when samples were cooled from $55^{\circ} \mathrm{C}$ to $-80{ }^{\circ} \mathrm{C}$ and reheated to ${ }^{\circ} \mathrm{C}$ at the mentioned rate. 


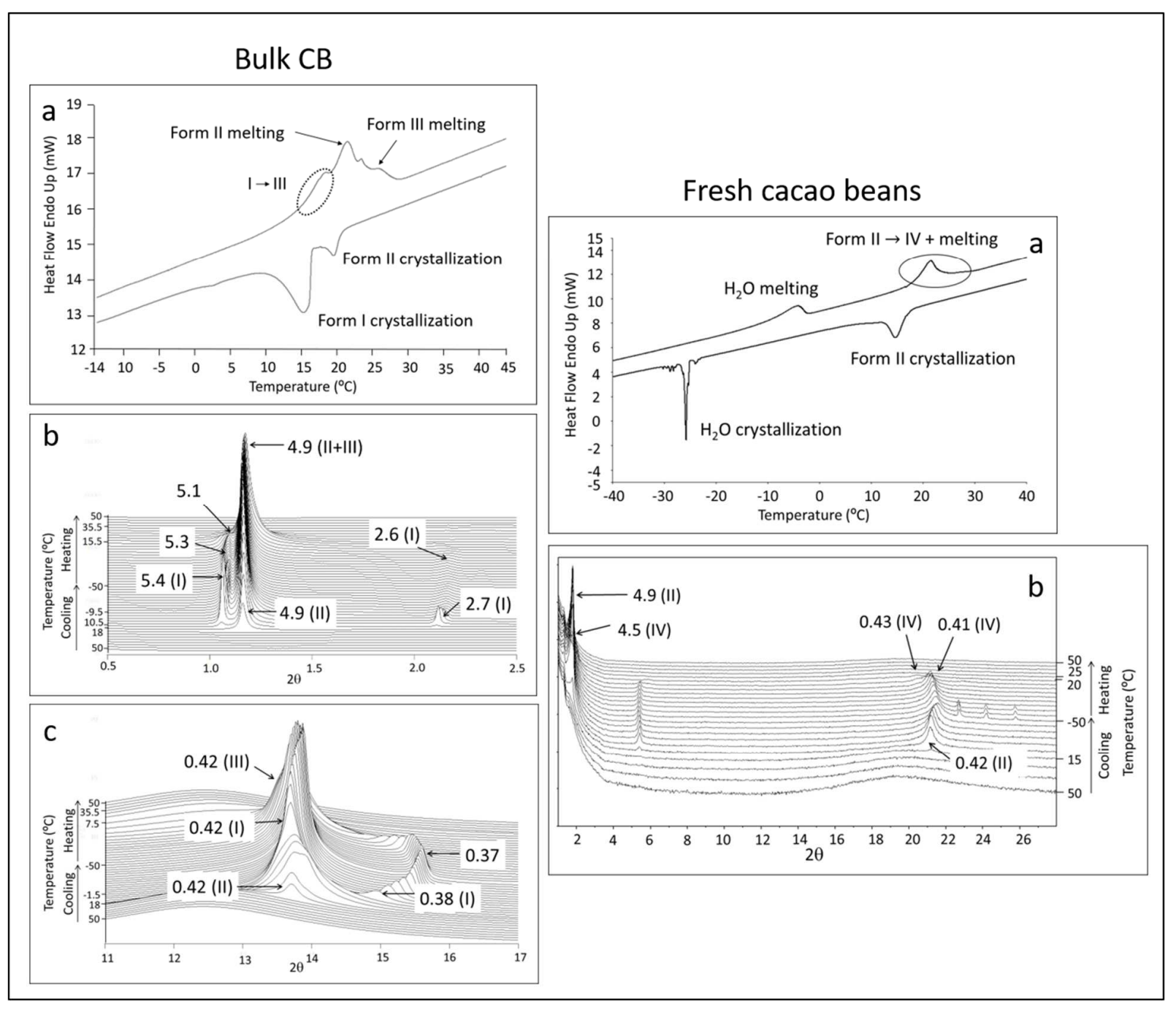

Figure 3. Polymorphic behavior of $\mathrm{CB}$ when cooled and heated at $2{ }^{\circ} \mathrm{C} / \mathrm{min}$. Bulk $\mathrm{CB}$ (left side); a) DSC thermogram; b) SR-SAXD pattern; c) SR-WAXD pattern. Fresh cacao beans (right side); a) DSC thermogram; b) Laboratory-scale XRD patterns.

As to bulk CB, by decreasing the cooling rate, two independent exothermic DSC signals appeared at $21.1{ }^{\circ} \mathrm{C}\left( \pm 1.8{ }^{\circ} \mathrm{C}\right)$ and $17.4{ }^{\circ} \mathrm{C}( \pm 0.4)$ (onset temperatures). According to the SRXRD data, these signals corresponded to form II and I crystallization, respectively. Form II was identified by small- and wide-angle peaks at $4.9 \mathrm{~nm}$ and $0.42 \mathrm{~nm}$, while SR-SAXD peaks at 5.4 
and $2.7 \mathrm{~nm}$, and SR-WAXD peaks at 0.42 and $0.38 \mathrm{~nm}$ were indicative of the occurrence of form I. By reheating the sample from $-80{ }^{\circ} \mathrm{C}$ to $55{ }^{\circ} \mathrm{C}$, the SR-XRD data revealed, at a temperature of around $15{ }^{\circ} \mathrm{C}$, the disappearance of form I SR-SAXD peak at $5.4 \mathrm{~nm}$ and an intensity decrease of the SR-WAXD peak at $0.42 \mathrm{~nm}$ and, soon after, peaks at $4.9 \mathrm{~nm}$ and $0.42 \mathrm{~nm}$, again, became more intense. Then, the first endothermic peak with $\mathrm{T}_{\text {onset }}$ of $13.3 \pm 0.4{ }^{\circ} \mathrm{C}$, may correspond to a polymorphic transformation from form I to form III. This peak was overlapped with other endothermic broad phenomena, which corresponded to the melting of forms II and III (onset and end temperatures of around $17.5{ }^{\circ} \mathrm{C}$ and $28.6{ }^{\circ} \mathrm{C}$, respectively), as typical SR-XRD peaks completely vanished and, at $35.5^{\circ} \mathrm{C}$, no peaks were present.

Simpler polymorphic behavior was noted in fresh cacao beans, as no form I crystallized from the molten $\mathrm{CB}$ and it directly crystallized into form II at around $15.9{ }^{\circ} \mathrm{C}$ (see Figure 3a, Fresh cacao beans and Table 2). In this case, polymorphic identification was carried out with laboratoryscale XRD (Figure 3b, Fresh cacao beans), and the results demonstrated initial crystallization of form II with typical peaks at 4.9 and $0.42 \mathrm{~nm}$. After that, the DSC cooling curve displayed a sharp exothermic phenomenon with approximate maximum temperature of $26{ }^{\circ} \mathrm{C}$, which was due to water crystallization. Ice crystals melted at a temperature slightly below $0{ }^{\circ} \mathrm{C}$ and, on further heating, temperature-dependent XRD patterns showed polymorphic transformation from form II to more stable form IV at around $20^{\circ} \mathrm{C}$, which was identified through its $4.9 \mathrm{~nm}$ peak in the smallangle region and 0.43 and $0.41 \mathrm{~nm}$ peaks in the wide-angle region. Soon after, around $5{ }^{\circ} \mathrm{C}$ further, these typical peaks vanished due to melting. Both polymorphic transformation and melting processes appeared as a single broad peak in the corresponding DSC heating thermogram, with onset and end temperatures of $15.9^{\circ} \mathrm{C}( \pm 1.9)$ and $27.7^{\circ} \mathrm{C}( \pm 1.8)$, respectively. 
Similarly to the previously described thermal treatment based on rapid cooling and heating of $15{ }^{\circ} \mathrm{C} / \mathrm{min}$, at intermediate rates of $2{ }^{\circ} \mathrm{C} / \mathrm{min}$, the initial crystallization temperature of the $\mathrm{CB}$ contained in fresh cacao beans was significantly lower (around $8{ }^{\circ} \mathrm{C}$, that is approximately 21.1 ${ }^{\circ} \mathrm{C}$ in bulk versus $16.4{ }^{\circ} \mathrm{C}$ in fresh beans) than in bulk state. Furthermore, the polymorphic crystallization and transformation was directed to obtain more stable forms, as no metastable form I was obtained in fresh beans, and form IV was not reached through polymorphic transformation in bulk.

The same behavior was monitored when lower rate of $0.5^{\circ} \mathrm{C} / \mathrm{min}$ was applied, as depicted in Figure 4. 


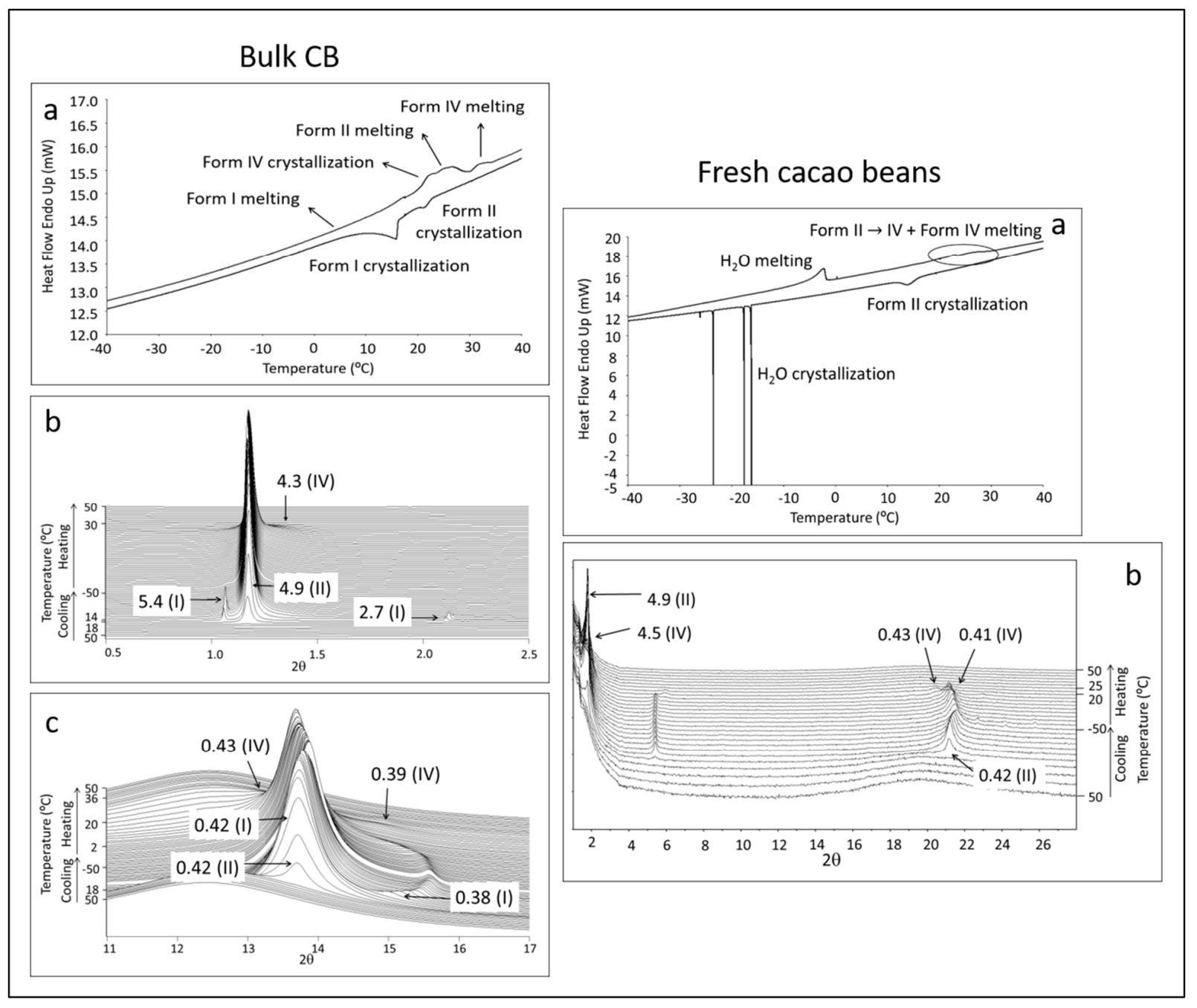

Figure 4. Polymorphic behavior of $\mathrm{CB}$ when cooled and heated at $0.5^{\circ} \mathrm{C} / \mathrm{min}$. Bulk $\mathrm{CB}$ (left side);

a) DSC thermogram; b) SR-SAXD pattern; c) SR-WAXD pattern. Fresh cacao beans (right side);

a) DSC thermogram; b) Laboratory-scale XRD patterns.

In bulk state, again forms II (with typical peaks at 4.9 and $0.42 \mathrm{~nm}$ ) and I (with peaks at 5.4 and $2.7 \mathrm{~nm}$, and 0.42 and $0.38 \mathrm{~nm}$ ) crystallized. Hence, form II and I crystallizations were assigned to exothermic DSC peaks with onset temperatures of $22.9 \pm 0.4{ }^{\circ} \mathrm{C}$ and $16.4 \pm 0.3{ }^{\circ} \mathrm{C}$, respectively. However, fewer amount of form I crystallized compared to that obtained at high and intermediate 
rates of 15 and $2{ }^{\circ} \mathrm{C} / \mathrm{min}$. When the crystallized sample was reheated from -80 to $55{ }^{\circ} \mathrm{C}$, form I SR-XRD peaks vanished at around $2{ }^{\circ} \mathrm{C}$ and no more changes, such as the occurrence of new peaks or the increase of the intensity of other existing peaks, occurred, so that we may assume that this form simply melted. On further heating, additional peaks at $4.3 \mathrm{~nm}$ (Figure 4b, Bulk CB) and 0.43 and $0.39 \mathrm{~nm}$ (Figure 4b, Bulk CB), corresponding to the form IV occurrence, were detected, and it was associated to the endothermic DSC peak with $\mathrm{T}_{\text {onset }}$ at around $19.6{ }^{\circ} \mathrm{C}$. Soon after, form II melted, so typical SR-XRD vanished and, finally, newly formed form IV also melted and this phenomenon corresponded to the last thermal event at approximately $30.7{ }^{\circ} \mathrm{C}$.

The polymorphic behavior observed in fresh cacao beans examined at the rates of $0.5^{\circ} \mathrm{C} / \mathrm{min}$ was similar to that examined at $2{ }^{\circ} \mathrm{C} / \mathrm{min}$ (see Figure 4, right side). Initial crystallization phenomenon occurred close to $6{ }^{\circ} \mathrm{C}$ lower than in bulk state, and it corresponded to form II crystallization $\left(\mathrm{T}_{\text {onset }}=16.6 \pm 1.1^{\circ} \mathrm{C}\right)$, which was identified through laboratory-scale XRD peaks at 4.9 and $0.42 \mathrm{~nm}$. At lower temperatures, a set of three sharp peaks were located within the range from $-17{ }^{\circ} \mathrm{C}$ to $-23{ }^{\circ} \mathrm{C}$, and it corresponded to the ice formation, which melted at a temperature close to $0{ }^{\circ} \mathrm{C}$ when the sample was subsequently heated. According to the XRD data, at around 20 ${ }^{\circ} \mathrm{C}$, new peaks at $4.5 \mathrm{~nm}$, and 0.43 and $0.41 \mathrm{~nm}$, corresponding to form IV, occurred at the expense of form II peaks. Then, close to $25^{\circ} \mathrm{C}$, form IV peaks disappeared due to melting. These processes of polymorphic occurrence and melting were assigned to a single broad and complex endothermic peak with onset temperature of $17.3{ }^{\circ} \mathrm{C}$ and end temperature of $30.0^{\circ} \mathrm{C}$.

Finally, lower rate of $0.1{ }^{\circ} \mathrm{C} / \mathrm{min}$ was employed in $\mathrm{CB}$ samples in bulk state and fresh cacao beans, as shown in Figure 5. 


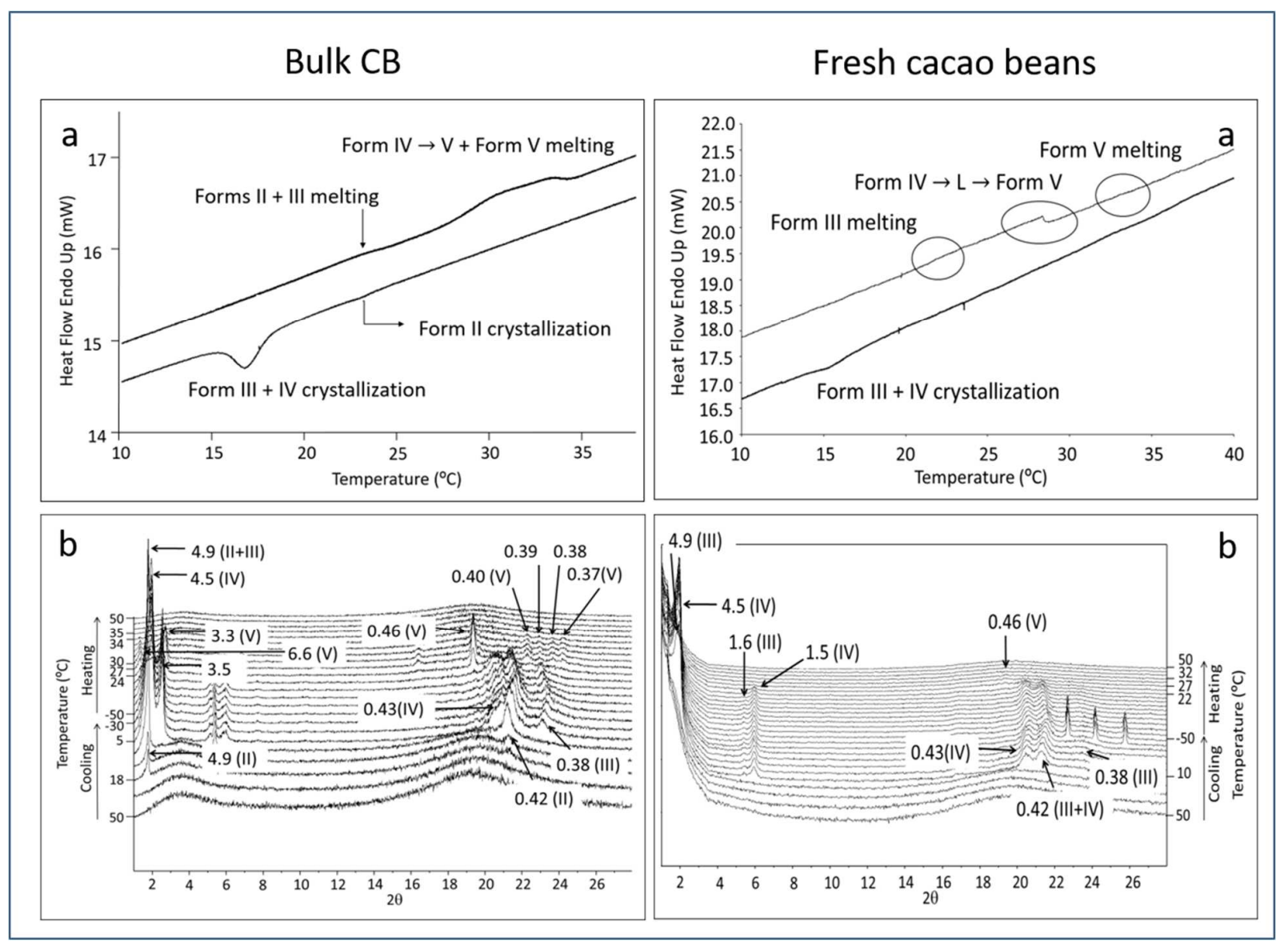

Figure 5. Polymorphic behavior of $\mathrm{CB}$ when cooled and heated at $0.1^{\circ} \mathrm{C} / \mathrm{min}$. Bulk $\mathrm{CB}$ (left side);

a) DSC thermogram; b) Laboratory-scale XRD patterns. Fresh cacao beans (right side); a) DSC thermogram; b) Laboratory-scale XRD patterns.

The DSC thermograms obtained by using this low rate were difficult to interpret in some cases, due to the flatness and complexity of some of the thermal events present, so that not all temperatures could be properly determined and the experimental error associated became particularly high, especially in the fresh cacao beans case. However, very detailed information was obtained with temperature-dependent laboratory-scale XRD experiments, so that the polymorphic behavior could be satisfactorily determined. The first thermal event, observed when CB bulk was 
cooled from $55{ }^{\circ} \mathrm{C}$ to $-80{ }^{\circ} \mathrm{C}$ at $0.1{ }^{\circ} \mathrm{C} / \mathrm{min}$, occurred at about $24.6{ }^{\circ} \mathrm{C}$ and, according to the laboratory-scale XRD data, it corresponded to form II crystallization, with typical small- and wideangle region peaks at 4.9 and $0.42 \mathrm{~nm}$. At lower temperatures of approximately $20.8^{\circ} \mathrm{C}$, additional exothermic DSC peak was detected (Figure 5a, Bulk CB) and, simultaneously, temperaturedependent XRD pattern demonstrated concurrent crystallization of forms III and IV, with long and short spacing values of 4.9 (form III) and $4.5 \mathrm{~nm}$ (form IV), and short spacing values of 0.43 (form IV) and $0.38 \mathrm{~nm}$ (form III). As to the heating stage, a very broad and flat endothermic peak was observed in the corresponding DSC curve, with onset and end temperatures of $18.3 \pm 0.8{ }^{\circ} \mathrm{C}$ and $24.8 \pm 0.5^{\circ} \mathrm{C}$, respectively. Within this temperature range, XRD peaks of previously crystallized forms II and III disappeared because of their melting. On further heating, new XRD peaks with long spacing values of 6.6 and $3.3 \mathrm{~nm}$, and short spacing values of $0.46,0.40$ and $0.37 \mathrm{~nm}$, corresponding to form $\mathrm{V}$ occurred, and their intensity increased at the expense of form IV peaks, due to a form IV $\rightarrow$ form V polymorphic transformation. Finally, form V melted. Both the formation of form $\mathrm{V}$ and its melting were assigned to the last broad endothermic DSC signal with $\mathrm{T}_{\text {onset }}$ of $28.0 \pm 1.1{ }^{\circ} \mathrm{C}$ and $\mathrm{T}_{\text {end }}$ of $34.6 \pm 0.7{ }^{\circ} \mathrm{C}$.

Again, the CB in fresh cacao beans exhibited much simpler polymorphic behavior compared to the bulk state at the same experimental conditions. By cooling at $0.1^{\circ} \mathrm{C} / \mathrm{min}$, molten $\mathrm{CB}$ directly crystallized into form III and IV (no form II was detected in this case), as XRD data demonstrated with the presence of small- and wide-angle diffraction peaks at 4.9 (form III) and 4.5 (form IV), and 0.43 (form IV), 0.42 (forms III and IV) and $0.38 \mathrm{~nm}$ (form III), respectively. These crystallization processes were attributed to the broad exothermic crystallization signal with initial temperature of about $18.8{ }^{\circ} \mathrm{C}$ and end temperature of $12.3{ }^{\circ} \mathrm{C}$. Regarding the DSC heating thermogram, as already stated, it was not possible to define properly the temperatures at which 
thermal events took place, due to their flatness (no data in Table 2). However, temperaturedependent XRD pattern permitted to define the sequence of polymorphic transformation and approximate temperatures. Then, at around $22{ }^{\circ} \mathrm{C}$, XRD peaks of form III vanished and, soon after, at $27^{\circ} \mathrm{C}$, form IV also melted, and new XRD peak at $0.46 \mathrm{~nm}$, typical of form V, occurred. Hence, form IV may have transformed to form V by melt-mediated polymorphic transformation. Finally, form $\mathrm{V}$ melted at around $32{ }^{\circ} \mathrm{C}$.

The polymorphic behavior of $\mathrm{CB}$ in bulk state and in fresh cacao beans under different cooling/heating conditions is summarized in Figure 6. In general, rapid cooling and heating rates leaded polymorphic crystallization and transformation to obtain less stable forms, whereas more stable forms predominated at low cooling and heating conditions, as already demonstrated by previous work on triacylglycerol components. ${ }^{10,14-16}$ 


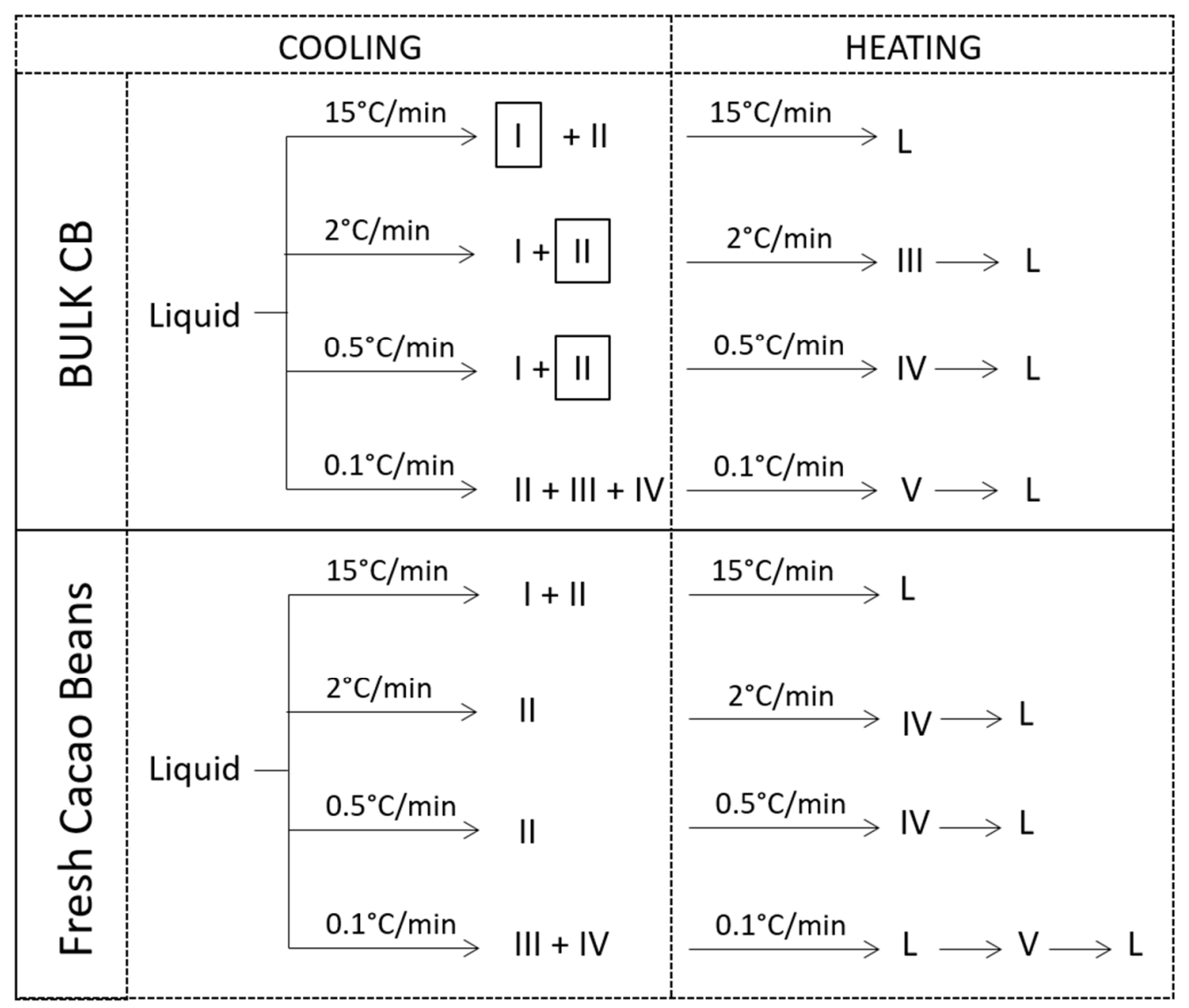

Figure 6. Polymorphic crystallization and transformation pathways of CB in bulk and fresh cacao beans under different cooling/heating conditions.

In more detail, in bulk state, concurrent crystallization of forms I and II was observed for cooling rates of 15,2 and $0.5{ }^{\circ} \mathrm{C} / \mathrm{min}$. However, the amount of form II increased at the expense of form I as the cooling rate decreased, as confirmed by the relative intensity of SR-SAXD peaks in Figures 2, 3 and 4. In other words, form I predominated at $15^{\circ} \mathrm{C} / \mathrm{min}$, whereas form II dominated for cooling rates of 2 and $0.5{ }^{\circ} \mathrm{C} / \mathrm{min}$, as pointed out in Figure 6 (squares). More stable forms II, III and IV crystallized from the melt at lower cooling rate of $0.1^{\circ} \mathrm{C} / \mathrm{min}$. As to the variation of heating rates and starting from form I and II crystals, they simply melted by quickly heating at $15{ }^{\circ} \mathrm{C} / \mathrm{min}$, 
whereas further polymorphic transformation to more stable forms took place at lower rates. Then, form III and IV were reached at heating rates of 2 and $0.5^{\circ} \mathrm{C} / \mathrm{min}$, respectively. More stable form V was obtained by heating crystals of form II, III and IV at the lowest rate of $0.1{ }^{\circ} \mathrm{C} / \mathrm{min}$.

$\mathrm{CB}$ in fresh cacao beans exhibited a simpler polymorphic behavior than that of $\mathrm{CB}$ in bulk state, and more stable polymorphic forms were obtained at the same experimental conditions. Similarly to the bulk case, concurrent crystallization of form I and II was obtained, but with higher predominance of form II than in bulk state (see relative stability of SR-SAXD peaks in Figure 2). Furthermore, no form I crystallized at 2 and $0.5^{\circ} \mathrm{C} / \mathrm{min}$ and only form II was present when cooling. Finally, form III and IV were obtained at $0.1{ }^{\circ} \mathrm{C} / \mathrm{min}$. Regarding the heating rates variation, forms I and II simply melted when heated at high rate of $15^{\circ} \mathrm{C} / \mathrm{min}$, as expected. However, polymorphic transformation from form II to form IV occurred at intermediate rates of 2 and $0.5{ }^{\circ} \mathrm{C} / \mathrm{min}$. Form V was achieved from form III and IV at the lowest heating rate of $0.1{ }^{\circ} \mathrm{C} / \mathrm{min}$.

In addition, the results showed that initial CB crystallization temperatures in fresh beans were lower by $\sim 4-6{ }^{\circ} \mathrm{C}$ than that of bulk at all experimental conditions. Furthermore, end crystallization temperatures were much lower in bulk than in fresh beans, so that $\Delta \mathrm{T}$ corresponding to the whole crystallization process was much higher in bulk $\left(\sim 10-19^{\circ} \mathrm{C}\right)$, as summarized in Table 3 . 
Table 3. Initial and end crystallization temperatures of $\mathrm{CB}$ in bulk and fresh cacao beans at different cooling conditions of $15,2,0.5$ and $0.1{ }^{\circ} \mathrm{C} / \mathrm{min}$.

\begin{tabular}{|l|l|l|l|l|}
\hline Cooling Rate $\left({ }^{\circ} \mathrm{C} / \mathrm{min}\right)$ & $\mathrm{CB}$ sample & $\mathrm{T}_{\text {onset }}\left({ }^{\circ} \mathrm{C}\right)$ & $\mathrm{T}_{\text {end }}\left({ }^{\circ} \mathrm{C}\right)$ & $\Delta \mathrm{T}\left({ }^{\circ} \mathrm{C}\right)$ \\
\hline \multirow{2}{*}{2} & Bulk & $16.6 \pm 0.5$ & $-21.1 \pm 0.6$ & 37.7 \\
\cline { 2 - 5 } & Fresh Bean & $12.9 \pm 0.7$ & $-5.7 \pm 1.2$ & 18.6 \\
\hline \multirow{2}{*}{0.5} & Bulk & $21.1 \pm 1.8$ & $-2.7 \pm 0.6$ & 23.8 \\
\cline { 2 - 5 } & Fresh Bean & $16.4 \pm 1.6$ & $5.4 \pm 1.7$ & 11.0 \\
\hline \multirow{2}{*}{0.1} & Bulk & $22.9 \pm 0.4$ & $7.5 \pm 1.0$ & 15.4 \\
\cline { 2 - 5 } & Fresh Bean & $16.6 \pm 1.1$ & $12.0 \pm 1.0$ & 4.6 \\
\hline & Bulk & $24.6 \pm 1.6$ & $15.6 \pm 0.8$ & 9 \\
\cline { 2 - 5 } & Fresh Bean* & $18.8 \pm 1.8$ & $12.3 \pm 0.4$ & 6.5 \\
\hline
\end{tabular}

* This peak was so flat (due to low rate and lower intensity of DSC signals compared to bulk) that the onset and end Ts were not so easy to define.

In order to understand the decreased crystallization temperature and different polymorphic behavior of $\mathrm{CB}$ contained in fresh cacao beans, one may pay attention to its microstructure. As studied by Lopez et al. (1987) ${ }^{1}$ with scanning electron microscopy techniques, most abundant cell types in cacao beans are small lipid/protein storage cells, which contain large number of lipid vacuoles or globules embedded in cytoplasm. That is, CB is contained in oil-in-water emulsion droplets (lipid bodies) of around 1-2 $\mu \mathrm{m}$ inside cacao beans (see Figure 1). Lipids in emulsion droplets crystallize and melt just like bulk lipids, but the kinetics of the processes may be different. Although emulsified fats melt about the same temperature as fats in bulk, they crystallize at much lower temperature, and this temperature may decrease as droplets diameter decreases. ${ }^{13}$ Recent work on thermodynamics and nucleation kinetics of lipid crystals in oil droplets was extensively reviewed by Sato and Ueno (2011), ${ }^{20}$ McClements (2012) ${ }^{21}$ and Povey (2014). ${ }^{22}$ As carefully 
described by McClements, the difference in the formation of nuclei due to supercooling in oil-inwater emulsions and bulk may be due to the extremely small volume of the lipid phase within each droplet. In bulk oil, the formation of nuclei usually occurs by heterogeneous nucleation, because of the presence of impurities or other substances. However, in emulsion state, it may proceed through homogeneous nucleation, as the probability of finding catalytic impurities in a droplet is so small. Therefore, in order to observe nucleation and crystallization, one may apply a higher supercooling to a lipid in emulsion than to the same lipid in bulk state.

Regarding the different polymorphic behavior observed in CB bulk and CB contained in fresh cacao beans, one may consider that polymorphic transformation tends to be much faster in emulsified lipids than in bulk oil, although some factors may modify this behavior, such as particle size, lipid type and the use of particular surfactant systems. The higher rate of polymorphic transformation in emulsion state has been attributed to smaller crystal size in emulsified fats compared to bulk, but also interfacial phenomenon. ${ }^{21}$

\section{Thermal analysis of cacao beans with different geographical origins}

We also determined the thermal behavior of fresh cacao beans with different geographical origins. Figure 7 shows DSC cooling (Figure 7a) and heating (Figure 7b) thermograms of fresh and dried cacao beans of Dominican Republic, Colombia, India and Philippines. The thermal program applied consisted of cooling melted CB from 55 to $-80{ }^{\circ} \mathrm{C}$ at a rate of $2{ }^{\circ} \mathrm{C} / \mathrm{min}$ and reheating to $55^{\circ} \mathrm{C}$ at the same rate. Onset and end temperatures corresponding to the crystallization and melting processes are detailed in Table 4. 

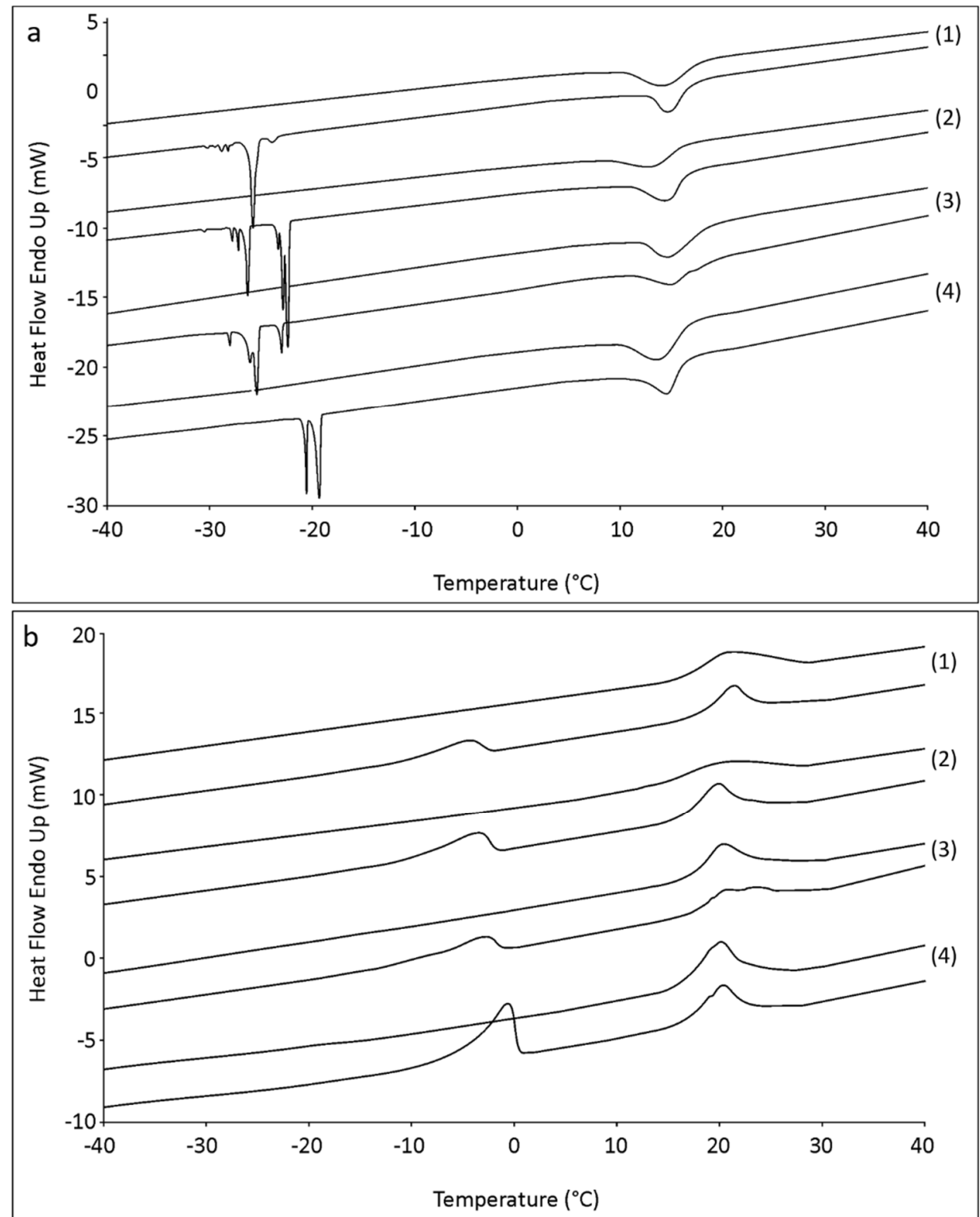

Figure 7. DSC cooling (a) and heating (b) thermograms of CB in cacao beans from different geographical origins obtained by cooling and heating at $2{ }^{\circ} \mathrm{C} / \mathrm{min}$ : (1) Dominican Republic; (2) Colombia; (3) India; (4) Philippines. In each pair of thermograms from each geographical origin, upper and lower DSC curves correspond to dried and fresh beans, respectively. 
Table 4. Initial and end crystallization and melting temperatures of CB in fresh cacao beans of different geographical origins

\begin{tabular}{|c|c|c|c|c|c|c|c|}
\hline \multirow[b]{2}{*}{$\begin{array}{l}\text { Geographical } \\
\text { origin }\end{array}$} & \multirow[b]{2}{*}{$\begin{array}{l}\text { Bean } \\
\text { sample }\end{array}$} & \multicolumn{3}{|c|}{ Crystallization } & \multicolumn{3}{|l|}{ Melting } \\
\hline & & $\mathrm{T}_{\text {onset }}\left({ }^{\circ} \mathrm{C}\right)$ & $\mathrm{T}_{\text {end }}\left({ }^{\circ} \mathrm{C}\right)$ & $\Delta \mathrm{T}\left({ }^{\circ} \mathrm{C}\right)$ & $\mathrm{T}_{\text {onset }}\left({ }^{\circ} \mathrm{C}\right)$ & $\mathrm{T}_{\text {end }}\left({ }^{\circ} \mathrm{C}\right)$ & $\Delta \mathrm{T}\left({ }^{\circ} \mathrm{C}\right)$ \\
\hline \multirow{2}{*}{$\begin{array}{l}\text { Dominican } \\
\text { Republic }\end{array}$} & Fresh & $16.4 \pm 1.6$ & $5.4 \pm 1.7$ & 11.0 & $16.5 \pm 1.4$ & $27.9 \pm 1.5$ & 11.4 \\
\hline & Dry & $17.6 \pm 1.2$ & $5.8 \pm 1.5$ & 11.8 & $16.7 \pm 1.0$ & $27.8 \pm 1.2$ & 11.1 \\
\hline \multirow{2}{*}{ Colombia } & Fresh & $15.8 \pm 1.1$ & $6.7 \pm 1.1$ & 9.1 & $11.8 \pm 1.1$ & $27.5 \pm 1.3$ & 15.7 \\
\hline & Dry & $15.7 \pm 1.1$ & $7.0 \pm 1.6$ & 8.7 & $12.3 \pm 0.7$ & $27.3 \pm 1.4$ & 15.0 \\
\hline \multirow{2}{*}{ India } & Fresh & $19.5 \pm 1.3$ & $9.3 \pm 1.4$ & 10.2 & $16.3 \pm 1.3$ & $30.0 \pm 1.1$ & 13.7 \\
\hline & Dry & $19.3 \pm 1.2$ & $9.5 \pm 1.0$ & 9.8 & $16.4 \pm 1.2$ & $30.1 \pm 1.4$ & 13.7 \\
\hline \multirow{2}{*}{ Philippines } & Fresh & $16.3 \pm 1.0$ & $9.0 \pm 1.0$ & 7.3 & $16.1 \pm 1.0$ & $27.3 \pm 0.9$ & 11.2 \\
\hline & Dry & $16.5 \pm 1.1$ & $9.5 \pm 1.1$ & 7.0 & $15.7 \pm 0.6$ & $27.6 \pm 1.2$ & 11.8 \\
\hline
\end{tabular}

The thermal behavior of fresh cacao beans having different geographical origins were essentially the same. As depicted in Figure 7a, DSC cooling curves consisted of two exothermic signals: a first one with $\mathrm{T}_{\text {onset }}$ between 15 and $20{ }^{\circ} \mathrm{C}$ due to $\mathrm{CB}$ crystallization, and another one between 20 and $30{ }^{\circ} \mathrm{C}$, corresponding to ice formation. Regarding the subsequent heating step (Figure $7 \mathrm{~b}$ ), ice melted at around $0{ }^{\circ} \mathrm{C}$, and $\mathrm{T}_{\text {onset }}$ of $\mathrm{CB}$ melting was observed within the temperature range from 12 to $17{ }^{\circ} \mathrm{C}$. No significant differences were detected between DSC thermograms of fresh and dried cacao beans having the same geographical origin, except for the presence of water in fresh beans. Furthermore, endothermic $\mathrm{CB}$ melting peaks became flatter in some dried samples, although onset and end temperatures were similar to those of fresh beans (see Table 4). 


\section{Rhizogenesis experiments}

The different crystallization behavior of emulsified CB in fresh cacao beans and CB in bulk state may explain germination conditions of cacao beans. We may assume that a condition for germination is that $\mathrm{CB}$ in cacao beans is in the liquid state, since enzymatic activity to convert $\mathrm{CB}$ to the nutrients for the germination of cacao bean is prohibited. In other words, no germination must occur when CB in intact cacao bean is in the solid state.

To demonstrate this, we conducted several rhizogenesis experiments by incubating fresh cacao beans under wet conditions at fixed and controlled temperatures of 17,20 and $32{ }^{\circ} \mathrm{C}$. Figure $8 \mathrm{a}$ shows resultant cacao beans after incubation for ten days at 32,20 and $17^{\circ} \mathrm{C}$.

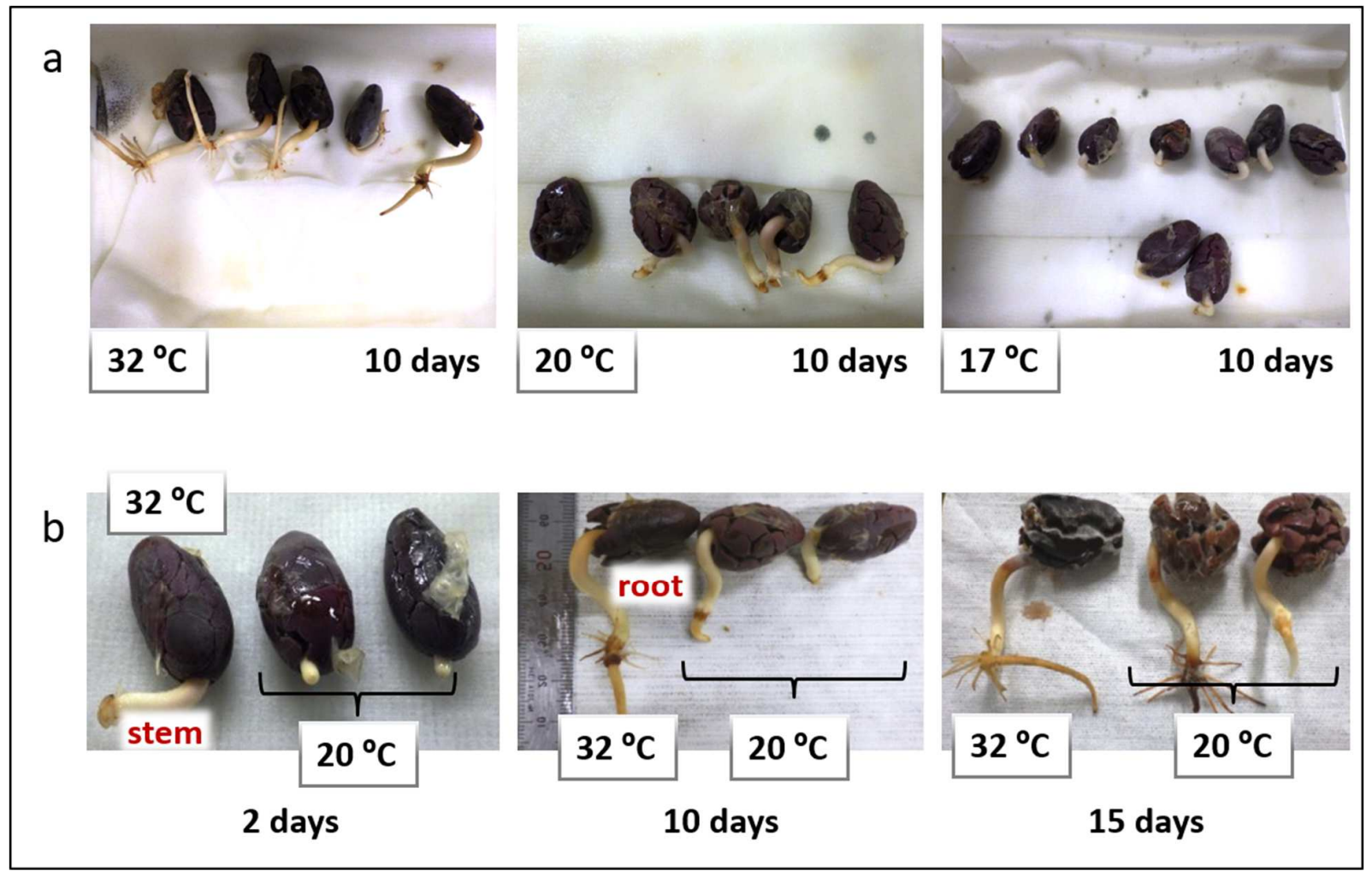

Figure 8. Stem and root shooting observed in fresh cacao beans when exposed at wet conditions a) At 32,20 and $17{ }^{\circ} \mathrm{C}$ for 10 days; b) At 32 and $20^{\circ} \mathrm{C}$ for 2,10 and 15 days. 
Rooting was detected at $32{ }^{\circ} \mathrm{C}$, whereas just stem shooting was observed at $20{ }^{\circ} \mathrm{C}$ and no significant changes occurred at $17{ }^{\circ} \mathrm{C}$ after ten days of incubation. The occurrence of stem and roots were noted just after 2 and 10 days of incubation at $32{ }^{\circ} \mathrm{C}$, respectively, and roots grew as the days went by (see Figure 8b). At a working temperature of $20{ }^{\circ} \mathrm{C}$, fresh beans did not experience any changes after two days of incubation, and stem emerged after 10 days. Finally, roots were developed after 15 days at $20^{\circ} \mathrm{C}$. These results proved that the occurrence of stem and rooting processes were promoted by increasing incubation temperatures, at which $\mathrm{CB}$ in fresh cacao beans remained in the liquid state. By contrast, at lower temperatures of $17^{\circ} \mathrm{C}$, which are close to onset crystallization temperature of $\mathrm{CB}$ in fresh beans at the experimental conditions analyzed (see Table 3), no rooting occurred. However, germination cannot occur below $18{ }^{\circ} \mathrm{C}$ due to $\mathrm{CB}$ crystallization. The fact that $\mathrm{CB}$ is in emulsion state in fresh cacao beans is the responsible for the lowering of Tc of $\mathrm{CB}$ compared to bulk state. As liquid state of $\mathrm{CB}$ is needed for cacao beans germination, growing environmental areas with temperatures higher than $16-17{ }^{\circ} \mathrm{C}$ are required. In other words, germination conditions of cacao beans are extended to low temperature environmental areas by lowering the Tc of CB in emulsion droplets than those in the bulk oil.

\section{CONCLUSIONS}

This study examined and compared the crystallization and polymorphic behavior of CB in fresh cacao beans and in bulk state at the same experimental conditions of varied cooling and heating rates. Simpler polymorphic behavior, based on the occurrence of more stable polymorphic forms, was observed in fresh cacao beans. Furthermore, CB in fresh cacao beans crystallized at significantly lower temperatures compared to bulk $\mathrm{CB}$, due to the presence of $\mathrm{CB}$ 
in the form of oil-in-water emulsion droplets. The thermal behavior of fresh cacao beans having different geographical origins was also analyzed, and no significant differences were detected between the different varieties. The results obtained in this work were consistent with rhizogenesis experiments at fixed temperatures, and permitted to relate the necessary conditions of germination of cacao beans at concrete growing environmental areas.

\section{AUTHOR INFORMATION}

\section{Corresponding Author}

Phone: +34 9340213 50. Fax: +34 9340213 40. E-mail: laurabayes@ub.edu

\section{ACKNOWLEDGEMENT}

The authors would like to thank the financial support of the Ministerio de Economía y Competitividad through Project MAT2015-65756-R. Funding from the Alba synchrotron facility for performing SR-XRD experiments is gratefully appreciated. SR-XRD experiments were conducted with the approval of the Alba Scientific Advisory Committee (proposal 2017022003). The authors thank Dr. Christina Kamma-Lorger, responsible for BL11-NCD at Alba, for his help.

The authors also acknowledge Maura Sans (IBK Tropic S. A.), David Peris (Chocolates Comes S.L.) and Marta Martín (Chocolate Academy, Barry Callebaut) for their assistance in obtaining fresh cacao pods having different geographical origins.

\section{REFERENCES}


1. Lopez, A. S.; Dimick, P. S.; Walsh, R. M. Scanning Electron Microscopy Studies of the Cellular Changes in Raw, Fermented and Dried Cocoa Beans. Food Structure 1987, 6, 916.

2. Vega, C.; Kwik-Uribe, C., in Cocoa Butter and Related Compounds; Garti, N., Widlak, N. R., Eds.; AOCS Press: Urbana, 2012, pp. 35-62.

3. Martin, S.; Parton, R. G. Lipid droplets: a unified view of a dynamic organelle. Nat. Rev. Mol. Cell Bio. 2006, 7, 373-378.

4. Wilflin, F.; Haas, J. T.; Walther, T. C.; Farese Jr., R. V. Lipid droplet biogenesis. Curr. Opin. Cell Biol. 2014, 29, 39-45.

5. Beckett's Industrial Chocolate Manufacture and Use; Beckett, S., Fowler, M.S., Ziegler, G.R., Eds. Wiley Blackwell: Oxford, 2017.

6. Timms, R. E. Confectionary Fats Handbook; The Oily Press: Bridgwater, UK, 2003.

7. Bayés-García, L.; Calvet, T.; Cuevas-Diarte, M. A.; Rovira, E.; Sato, K. New Textures of Chocolate Are Formed by Polymorphic Crystallization and Template Effect: Velvet Chocolate. Cryst. Growth Des. 2015, 15, 4045-4054.

8. Sato, K.; Arishima, T.; Wang, Z. H.; Ojima, K.; Sagi, N.; Mori, H. Polymorphism of POP and SOS. I. Occurrence and polymorphic transformation. J. Am. Oil Chem. Soc. 1989, 66, 664-674.

9. Koyano, T.; Hachiya, I.; Arishimo, T.; Sato, K.; Sagi, N. Polymorphism of POP and SOS. II. Kinetics of melt crystallization. J. Am. Oil Chem. Soc. 1989, 66, 675-679. 
10. Bayés-García, L.; Calvet, T.; Cuevas-Diarte, M. A.; Ueno, S.; Sato, K. In situ observation of transformation pathways of polymorphic forms of 1,3-dipalmitoyl-2-oleoyl glycerol (POP) examined with synchrotron radiation X-ray diffraction and DSC. CrystEngComm 2013, 15, 302-314.

11. Arishima, T.; Sagi, N.; Mori, H.; Sato, K. Polymorphism of POS. I. Occurrence and polymorphic transformation. J. Am. Oil Chem. Soc. 1991, 68, 710-715.

12. Rousset, P.; Rappaz, M. Polymorphism and mixing phase behavior of major triacylglycerols of cocoa butter. J. Am. Oil Chem. Soc. 1997, 74, 1693-1697.

13. Coupland, J. N., in Crystallization of Lipids. Fundamentals and Applications in Food, Cosmetics, and Farmaceuticals; Sato, K., Ed.; Wiley Blackwell: Hoboken, 2018, pp. 431446.

14. Bayés-García, L.; Calvet, T.; Cuevas-Diarte, M. A.; Ueno, S.; Sato, K. In situ synchrotron radiation X-ray diffraction study of crystallization kinetics of polymorphs of 1,3-dioleoyl-2-palmitoyl glycerol (OPO). CrystEngComm. 2011, 13, 3592-3599.

15. Bayés-García, L.; Calvet, T.; Cuevas-Diarte, M. A.; Ueno, S.; Sato, K. Crystallization and Transformation of Polymorphic Forms of Trioleoyl Glycerol and 1,2-Dioleoyl-3-raclinoleoyl Glycerol. J. Phys. Chem. B 2013, 117, 9170-9181.

16. Bayés-García, L.; Calvet, T.; Cuevas-Diarte, M. A.; Ueno, S. In situ crystallization and transformation kinetics of polymorphic forms of saturated-unsaturated-unsaturated triacylglycerols: 1-palmitoyl-2,3-dioleoyl glycerol, 1-stearoyl-2,3-dioleoyl glycerol, and 1-palmitoyl-2-oleoyl-3-linoleoyl glycerol. Food Res. Int. 2016, 85, 244-258. 
17. Lehrian, D.W.; Keeney, P.G.; Butler, D.R. Triglyceride Characteristics of Cocoa Butter from Cacao Fruit Matured in a Microclimate of Elevated Temperature. J. Am. Oil Chem. Soc. 1980, 57, 66-69.

18. Leathers, R.R.; Scragg, A.H. The effect of different temperatures on the growth, lipid content and fatty acid composition of Theobroma Cacao cell suspension cultures. Plant Sci. 1989, 62, 217-227.

19. Perkin Elmer (1982). Instructions model DSC-4. (Norwalk, Connecticut, USA).

20. Sato, K.; Ueno, S. Crystallization, transformation and microstructures of polymorphic fats in colloidal dispersion states. Curr. Opin. Colloid In. 2011, 16, 384-390.

21. McClements, D. J. Crystals and crystallization in oil-in-water emulsions: Implications for emulsion-based delivery systems. Adv. Colloid Interfac. 2012, 174, 1-30.

22. Povey, M. J. W. Crystal nucleation in food colloids. Food Hydrocolloid 2014, 42, 118 129. 


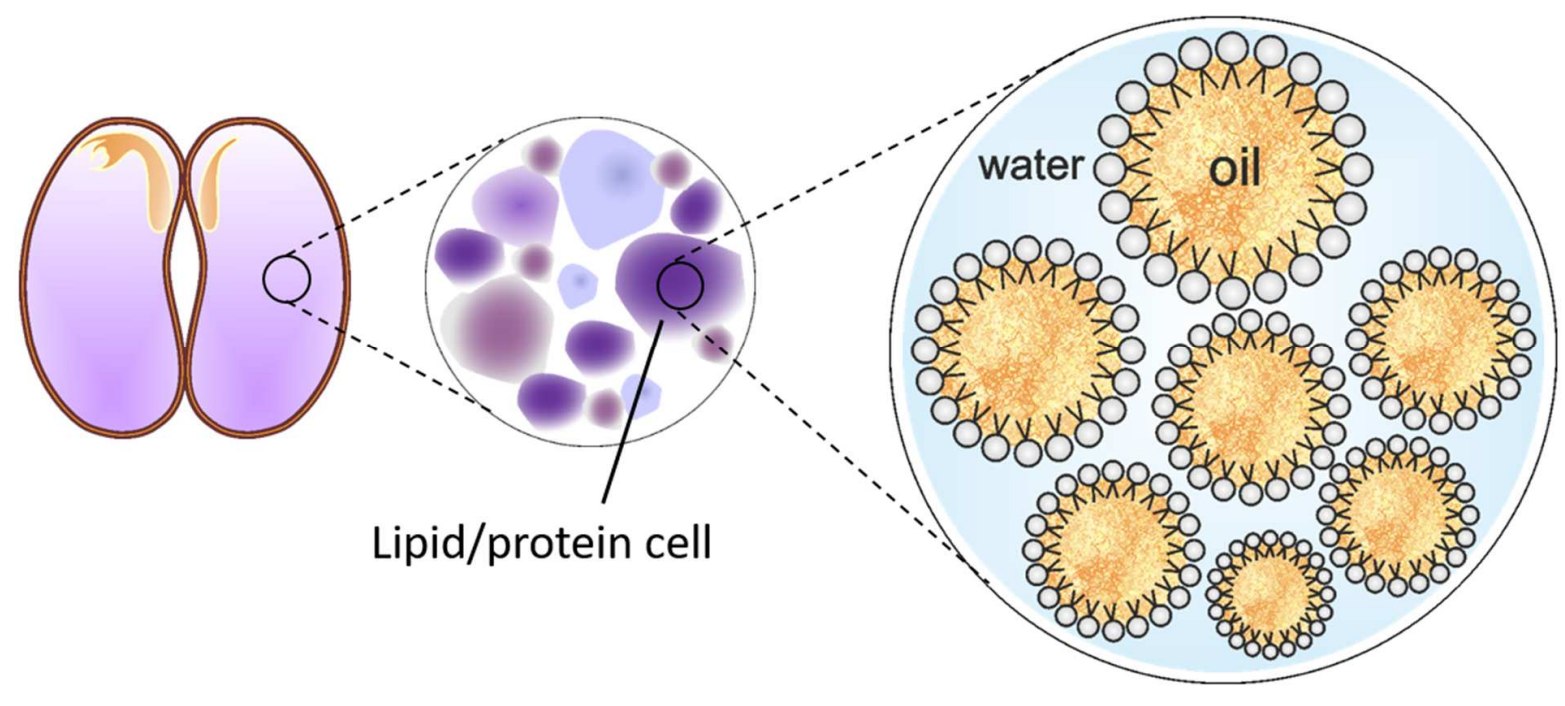

The crystallization behavior of cocoa butter in fresh cacao beans determine the necessary conditions of germination of cacao beans at concrete growing environmental areas. 